\title{
Effects of Surface Coating Preparation and Sliding Modes on Titanium Oxide Coated Titanium Alloy for Aerospace Applications
}

\author{
Bo Yuan Peng, ${ }^{1,2}$ Xueyuan Nie, ${ }^{1}$ and Ying Chen ${ }^{1}$ \\ ${ }^{1}$ Mechanical, Automotive and Materials Engineering, University of Windsor, Windsor, ON, Canada N9B 3P4 \\ ${ }^{2}$ Cranbrook Kingswood Schools, Bloomfield Hills, MI 48304, USA \\ Correspondence should be addressed to Xueyuan Nie; xnie@uwindsor.ca
}

Received 7 December 2013; Revised 5 February 2014; Accepted 6 February 2014; Published 6 May 2014

Academic Editor: Nicolas Avdelidis

Copyright (C) 2014 Bo Yuan Peng et al. This is an open access article distributed under the Creative Commons Attribution License, which permits unrestricted use, distribution, and reproduction in any medium, provided the original work is properly cited.

\begin{abstract}
This paper investigates the mechanical response of a coated Ti-6Al-4V alloy surface under different sliding contact stress conditions. The surface was coated with an oxide ceramic material created through the use of a recently developed technique known as plasma electrolytic oxidation (PEO). During the PEO procedure, a composition of silicate and phosphate was used as the electrolyte. In order to evaluate the coating, pin-on-disk (POD) tribology tests and cyclic inclined sliding tests were used under dry room conditions. Furthermore, scanning electron microscopy (SEM) and energy dispersive spectroscopy (EDS) were utilized to examine the morphology and composition of the coating surfaces. The results of the POD tests revealed that the PEO coating could have a low coefficient of friction and suggested that high silicon concentrations in the PEO coatings take away oxygen from stoichiometric Ti oxides to create lubricating oxides. In addition, cyclic inclined sliding tests showed that smaller pores on the surface of the coating could permit a higher coating cohesive strength and allow the coated Ti alloy surface to perform better under high inclined sliding forces.
\end{abstract}

\section{Introduction}

A variety of titanium alloys are used in the aerospace industry for landing systems, fasteners, engine components, airframes, and others. Of these alloys, the Ti-6Al-4V stands out for its high strength-to-weight ratio, corrosion resistance, and low density. However, because of its poor wear resistance properties, especially against abrasive wear, the Ti-6Al-4V does not perform well in sliding components and parts that undergo high friction. As a result, aircrafts that contain this alloy, though built strong, are subject to maintenance and repair that create high expenses. In order to combat this issue, many coating techniques such as physical/chemical vapor deposition (PVD/CVD), ion implementation, and surface oxidation have been developed to strengthen the wear resistance of the alloy [1]. Although each of these techniques has its merits, PVD/CVD may create coatings with insufficient adhesion and ion implementation treatments are often too thin for industrial applications (less than $5 \mu \mathrm{m}$ ). Yet, while conventional oxidation methods seem to be the most popular choice, they may worsen the mechanical and/or corrosion properties of the alloy.

Coatings such as silicon incorporated diamond-like coating (Si-DLC) made by plasma assisted CVD [2] and those made from laser diffusion nitriding [3] have also been developed to improve the wear properties of Ti-6Al-4V. However, these techniques also have their disadvantages as well. While Si-DLC has been proven to improve the wear resistance of the titanium alloy, the coating provides less benefit under wet conditions due to the pinholes in the coating which allows the penetration of water and other ions through the coating, corroding the substrate and thus, the coating adhesion is weakened around those areas [2]. Laser diffusion nitriding has also been shown to enhance the wear properties of the alloy without melting it [3]. However, such treatment is often expensive due to the equipment needed.

Recently, a new technique called plasma electrolytic oxidation (PEO) has been developed to retain benefits of conventional surface oxidation $[1,4]$. This form of oxidation, although similar to the anodizing process, uses extremely 
TABLE 1: Chemical composition of Ti-6Al-4V in weight percent.

\begin{tabular}{lccccccccc}
\hline Element & $\mathrm{Al}$ & $\mathrm{V}$ & $\mathrm{Fe}$ & $\mathrm{O}$ & $\mathrm{C}$ & $\mathrm{N}$ & $\mathrm{H}$ & $\mathrm{Others}$ & $\mathrm{Ti}$ \\
\hline Weight percent & $5.5-6.75$ & $3.5-4.5$ & 0.25 (maximum) & 0.2 (maximum) & 0.08 & 0.5 & 0.0125 & 0.1 & Balance \\
\hline
\end{tabular}

high voltage above the breakdown voltage to create microdischarges on the anode surface. Due to the high temperature and plasma oxidation of the interaction, a coating comprised of complex oxide compounds is produced. Although the top surface of the coating is relatively porous and loose, the inner layer is much denser and uniform.

PEO coatings can be used in various fields ranging from biomedical applications to the automotive industry. In fact, much research has been done with PEO coatings on different metals and alloys such as magnesium and titanium biomedical materials in simulated human body environment [4-12]. Furthermore, tests concerning the performance of the coating on an A356 alloy commonly used in the automobiles have also been conducted and discussed [13]. Yet, while PEO coatings have performed well under conditions related to these areas, more research needs to be done for the tribologically concerned coating application in the aerospace industry. Furthermore, not much testing has been done on PEO coatings using the new cyclic inclined testing method developed at the University of Windsor for the purpose of observing how surfaces would react to high forces during the inclined sliding and wear test $[14,15]$.

A previous paper [16] has studied tribological property of relatively thin coatings $(10-27 \mu \mathrm{m}$ in thickness as prepared before polishing, around $10 \mu \mathrm{m}$ in thickness after polishing for tribotests). This paper was to study thicker coatings (38-65 $\mu \mathrm{m}$ thick before polishing, 20-30 $\mu \mathrm{m}$ after polishing) and investigate the coating thickness effect on tribological behaviors. The thick coatings are quite rough; polishing the coatings down to 20-30 microns thick was to obtain a fairly smooth surface $R_{a}=0.15$ microns for all tested coating sample surfaces to avoid possible effect of roughness difference on the coefficient of friction.

Consequently, accelerated laboratory lab tests like the one mentioned earlier were used to investigate how PEOcoated titanium alloys would likely perform under different applications in aerospace. Components like those found in landing gear systems often need to sustain the entire weight of an aircraft at high speeds during landing and departure [17]. As a result, these parts would need to sustain heavy wear. However, since many landing gear systems are idle during flight, they do not endure constant stress. On the other hand, small components such as bearings, fasteners, and discs may not need to sustain a lot of force but are subject to continuous wear. Consequently, this study examines the wear behaviour of a PEO-coated Ti alloy with different coating thicknesses under high force with short testing periods and low force with prolonged testing periods.

\section{Experimental Details}

2.1. Preparation of Sample Coupon. In this study, Ti-6Al$4 \mathrm{~V}$ was used to prepare two samples as substrate material

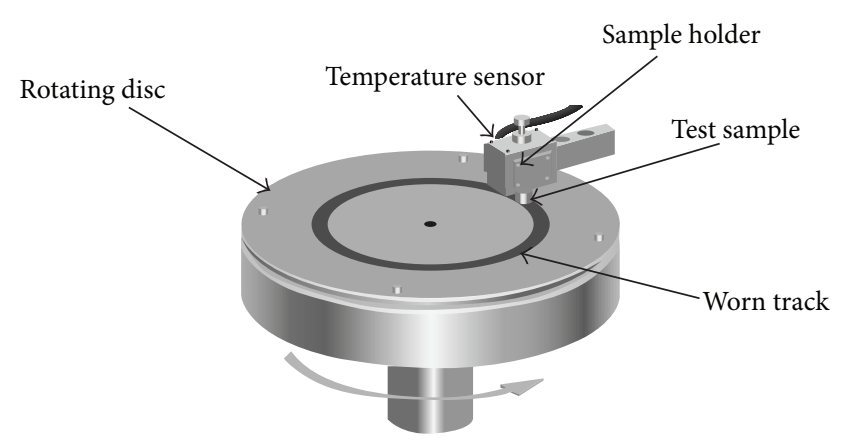

FIGURE 1: Diagram of pin-on-disk (POD) tribotests.

with dimensions of around $25 \mathrm{~mm} \times 25 \mathrm{~mm} \times 6.5 \mathrm{~mm}$. The composition of the Ti-6Al-4V can be found in Table 1 . After being cut, the samples, S1 and S2, were thoroughly polished using sandpaper up to grade P2500 so that their roughness would be $R_{a} \approx 0.15 \mu \mathrm{m}$. Lastly, the samples were cleaned with acetone, rinsed with distilled water, and set to dry in room conditions $\left(20^{\circ} \mathrm{C}, 65 \%\right.$ humidity, $\left.1 \mathrm{~atm}\right)$.

2.2. PEO Treatment. A solution containing 3 liters of distilled water, $18 \mathrm{~g}$ of $\mathrm{Na}_{2} \mathrm{SiO}_{3}$, and $12 \mathrm{~g}$ of $\mathrm{Na}_{3} \mathrm{PO}_{4}$ was created to make a $6 \mathrm{~g} / \mathrm{L} \mathrm{Na} \mathrm{SiO}_{3}+4 \mathrm{~g} / \mathrm{L} \mathrm{Na} \mathrm{NO}_{4}$ electrolyte for the $\mathrm{PEO}$ procedure. The samples, connected to an AC power source in order to act as the anode by a titanium wire, were completely submerged in the solution sink and a stainless steel plate served as the cathode. For more information on the parameters of the preparations, please refer to Table 2. After the coating deposition was completed, the coated samples were washed with distilled water and cleaned with acetone to remove any leftover solution and residue left on them. Following that, they were left to dry in room conditions.

2.3. Thickness Measurement. In order to determine the thickness of the coating, a Positector 6000 was used to take more than ten measurements from each sample on both sides. Consequently, an accurate average could be calculated using the data collected. Furthermore, because it was necessary to determine coating thicknesses that produced optimal results, both samples underwent pin-on-disc tribotests and inclined sliding tests at different thicknesses. As a result, each sample was polished carefully using sandpaper up to P2500 in grade to approach the desired thicknesses measured by the Positector 6000 and tested using the methods mentioned earlier. For information on the original and polished thicknesses of the samples, please refer to Table 3 .

2.4. Pin-on-Disk Testing. Pin-on-disk (POD) tribotests (see Figure 1) were carried out on the coatings to determine the effects of pure sliding on the coatings of different thicknesses and different preparations. A POD tribometer and Surfcorder 


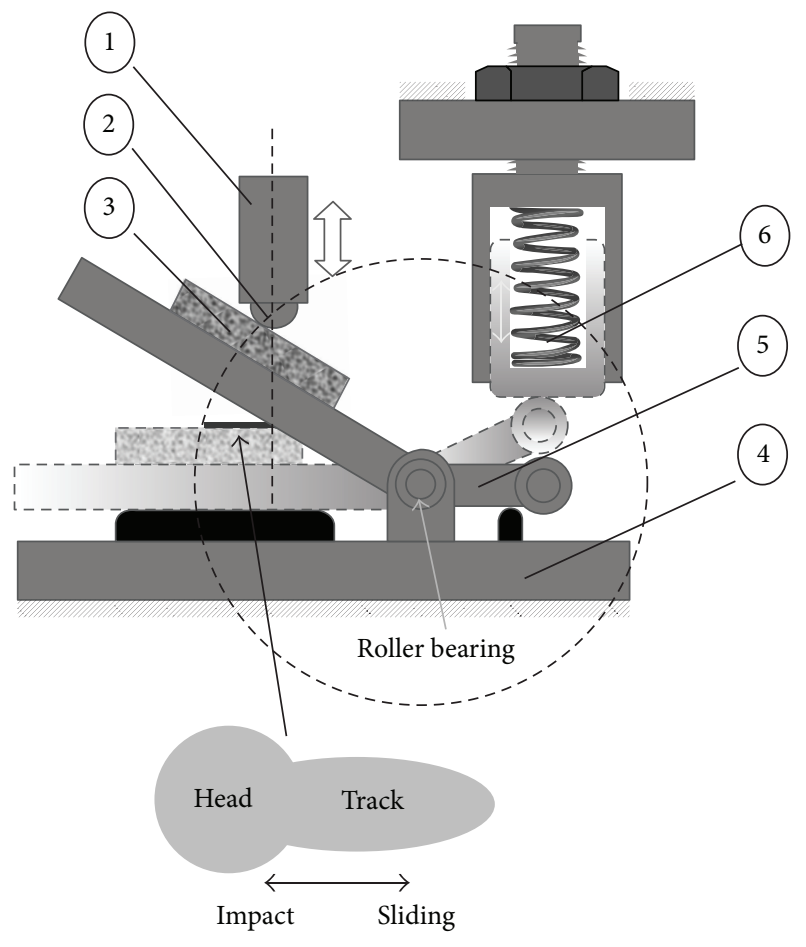

(a)

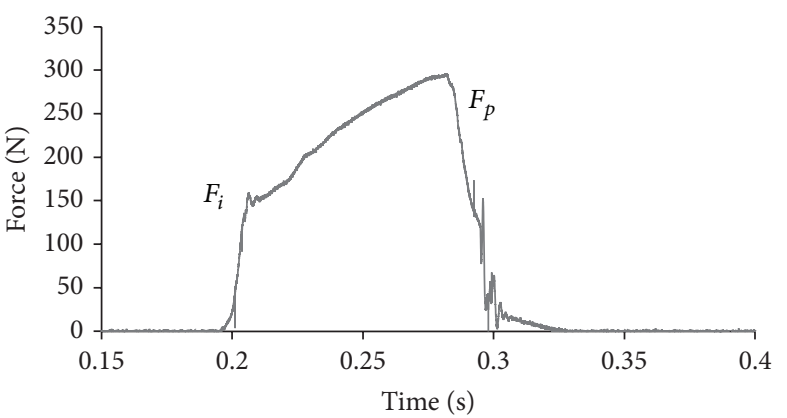

(b)

FIGURE 2: Impact sliding test method [14]. (a) Diagram of the impact sliding test method with labelled components, where 1 is ball specimen drive (e.g., air cylinder), 2 is ball specimen, 3 is flat specimen (i.e., coating), 4 is rigid frame, 5 is rotatable rocker, and 6 is return drive (e.g., spring). (b) Load versus time graph of surface undergoing the impact sliding test method.

TABLE 2: Parameters for the PEO preparation of the samples.

\begin{tabular}{lccc}
\hline Parameter & $\begin{array}{c}\text { Treatment time } \\
\text { (in minutes) }\end{array}$ & $\begin{array}{c}\text { Power supply } \\
\text { mode }\end{array}$ & $\begin{array}{c}\text { Current density } \\
\text { (in } \mathrm{mA} / \mathrm{mm}^{2} \text { ) }\end{array}$ \\
\hline S1 & 45 & Bipolar & $1.5 /-0.5$ \\
S2 & 25 & Bipolar & $1.5 /-0.5$ \\
\hline
\end{tabular}

TABLE 3: Original and polished thicknesses of the PEO coatings.

\begin{tabular}{lcc}
\hline Samples & $\begin{array}{c}\text { Original coating } \\
\text { thickness }\end{array}$ & $\begin{array}{c}\text { Polished coating } \\
\text { thickness }\end{array}$ \\
\hline S1-side A & $65.4 \mu \mathrm{m}$ & $20 \mu \mathrm{m}$ \\
S1-side B & $65.4 \mu \mathrm{m}$ & $30 \mu \mathrm{m}$ \\
S2-side A & $38.5 \mu \mathrm{m}$ & $20 \mu \mathrm{m}$ \\
S2-side B & $38.5 \mu \mathrm{m}$ & $30 \mu \mathrm{m}$ \\
\hline
\end{tabular}

made by SCILAND Co. and steel pin balls (AISI 52100, HRC $58-60$, and $5.5 \mathrm{~mm}$ in diameter) acting as the counterface material were used in the testing process. This set-up allows pure sliding to be achieved through the rotation of the sample while keeping the counterface material static. Furthermore, all samples were tested in dry room conditions and under $2 \mathrm{~N}$ of normal load. The sliding speed was $0.075 \mathrm{~m} / \mathrm{s}$. In order to prevent contaminations and minimize result error, both the coatings and the steel pin ball counterface material were cleaned with acetone thoroughly before and after each POD test. To quantitatively investigate the effects of pure sliding on the coatings, the coefficient of friction (C.O.F.) was recorded during each test using a data acquisition system. Four coating surfaces (S1 at $20 \mu \mathrm{m}$ thickness, S1 at $30 \mu \mathrm{m}$ thickness, S2 at $20 \mu \mathrm{m}$ thickness, and S2 at $30 \mu \mathrm{m}$ thickness) and the polished substrate were tested using this method. According to the results of tests, severe materials transferring from the counterface ball had occurred and caused abrasive wear behaviour when the C.O.F. value reached around 0.65 [16]. Consequently, the POD tests were conducted on each coating/substrate testing couple until either the C.O.F. value maintained a stable value of 0.65 or the C.O.F. value did not appear to show any signs of reaching 0.65 after approximately $1200 \mathrm{~m}$ test. Thus, some coatings underwent longer POD sliding distances than others to ensure that qualitative analysis of the testing would be accurate.

2.5. Inclined Sliding Test. A recently new inclined impact sliding test method developed at the University of Windsor $[14,15]$ was used to investigate the wear behaviour of the coatings under extremely high combined attack of impact and sliding forces. The details of the testing instrument and procedure can be found in [14]. By taking advantage of the repeating vertical motion of the hard counterface material, the surface of the coating can be continually attacked at an angle (around 15-20 degree) to create constant impact, $F_{\mathrm{i}}$, and pressing, $F_{\mathrm{p}}$, forces on it (see Figure 2). The value of $F_{\mathrm{i}}$ and $F_{\mathrm{p}}$ can be mechanically adjusted from zero to several hundred Newtons before the test, thus allowing for the simulation 


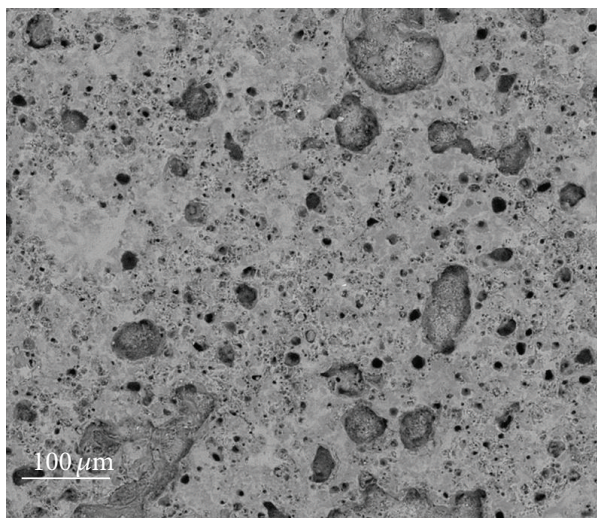

(a)

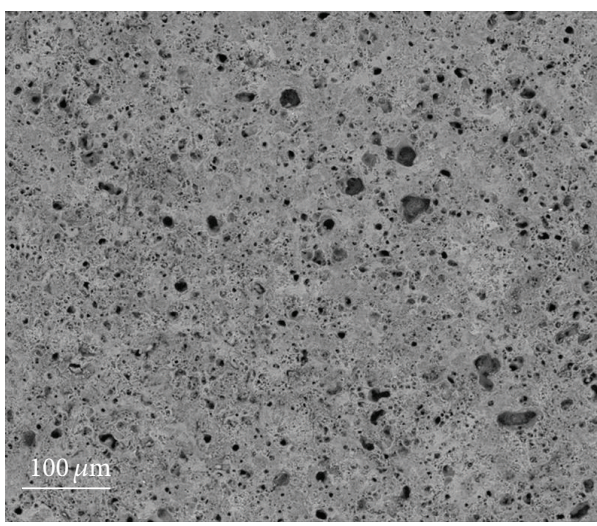

(c)

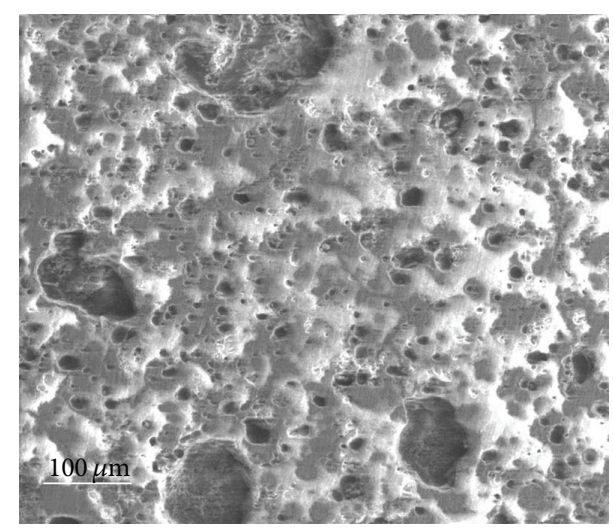

(b)

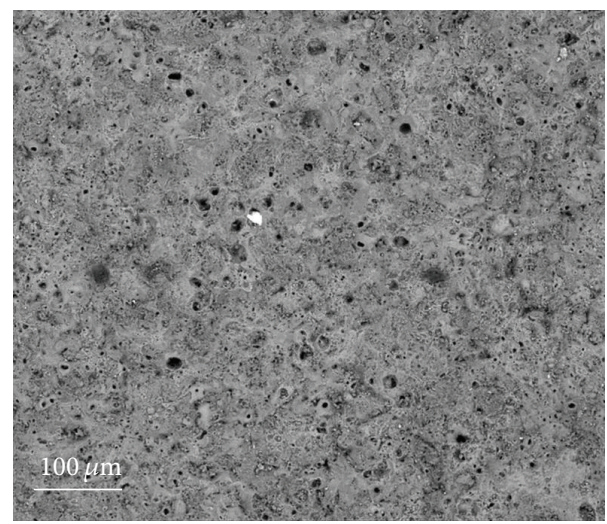

(d)

FigurE 3: SEM micrographs of the four coating surfaces (a) S1 at $20 \mu \mathrm{m}$ thickness, (b) S1 at $30 \mu \mathrm{m}$ thickness, (c) S2 at $20 \mu \mathrm{m}$ thickness, and (d) S2 at $30 \mu \mathrm{m}$ thickness.

of different conditions. However, because the objective of this paper is to investigate the effects of sliding modes on the coating, not dynamic impact load, $F_{\mathrm{i}}$ was set to zero. To ensure that the testing instrument would not distribute dynamic impact load, the coating was elevated to the point of contact with the counterface material after it was fixed tightly on the sample holder (component 5, Figure 2). The pressing force was a cyclic pulsed load and the loading curve of each cycle is shown in Figure 2. All tests were conducted using a steel pin ball (AISI 52100, HRC 58-60, and $10 \mathrm{~mm}$ in diameter) as the counterface material and $300 \mathrm{~N}$ of pressing load (the maximum Hertz contact stress was calculated to be approximately: $2.0 \mathrm{GPa}[18]$ ). Four coating surfaces (S1 at $20 \mu \mathrm{m}$ thickness, $\mathrm{S} 1$ at $30 \mu \mathrm{m}$ thickness, $\mathrm{S} 2$ at $20 \mu \mathrm{m}$ thickness, and S2 at $30 \mu \mathrm{m}$ thickness) were tested using this method under room conditions at $2.5 \mathrm{~Hz}$ for 50 cycles.

2.6. Optical Microscopy and Scanning Electron Microscopy. To diminish error caused by time, optical microscopy (OM) was used to examine the wear tracks from the POD and the sliding scars from the sliding experiments immediately after each test. In addition, scanning electron microscopy (SEM) with an energy dispersive X-ray (EDX) was used to further analyze the wear behavior of the coating under different sliding modes.

\section{Observations and Results}

3.1. Coating Observations. SEM micrographs and EDX analysis of the polished coating surfaces are shown in Figure 3. PEO coatings normally contain two layers. On the surface, there is a thick, porous outer layer. However, the inner layer of the coating is thin and dense. Paying attention to the SEM micrographs the size of pores on the S1 surfaces is much wider than that on the S2. While the largest pores on both S2 surfaces are only $30-40 \mu \mathrm{m}$ in diameter, those on S1 had diameters up to $100 \mu \mathrm{m}$. One possible explanation for this phenomenon can be based on the different treatment times of the two samples. According to [19], the density of the sparking during the coating process decreases as the treatment progresses. However, the power of these sparks increases. Since the sparking is attributed to the formation of the coating, the decrease in spark density over time can result in a less uniform coating. This assumption agrees with the SEM micrographs in Figure 3. Because the S1 was treated for a longer time than S2 at the same current density, the decrease in the density of sparks and the increase in intensity of each spark discharging in the later stages $\left(U_{6}-U_{7}\right)$ of the treatment could explain the larger pores found in the sample. Meanwhile, since S2 was only treated for 25 minutes, higher spark density at the end of 
TABLE 4: The atomic ratio of oxygen versus cations on the polished coating surfaces.

\begin{tabular}{lcr}
\hline Surface & Atomic ratio on coating O/All & Stoichiometric expression \\
\hline S1 $20 \mu \mathrm{m}$ & 1.78 & $\left(\mathrm{Ti}_{0.227} \mathrm{Al}_{0.035} \mathrm{Si}_{0.685} \mathrm{P}_{0.053}\right) \mathrm{O}_{1.782}$ \\
S1 $30 \mu \mathrm{m}$ & 1.81 & $\left(\mathrm{Ti}_{0.167} \mathrm{Al}_{0.028} \mathrm{Si}_{0.756} \mathrm{P}_{0.048}\right) \mathrm{O}_{1.782}$ \\
$\mathrm{~S} 220 \mu \mathrm{m}$ & 1.82 & $\left(\mathrm{Ti}_{0.249} \mathrm{Al}_{0.031} \mathrm{Si}_{0.676} \mathrm{P}_{0.045}\right) \mathrm{O}_{1.815}$ \\
$\mathrm{~S} 230 \mu \mathrm{m}$ & 1.88 & $\left(\mathrm{Ti}_{0.173} \mathrm{Al}_{0.028} \mathrm{Si}_{0.763} \mathrm{P}_{0.035}\right) \mathrm{O}_{1.887}$ \\
\hline
\end{tabular}

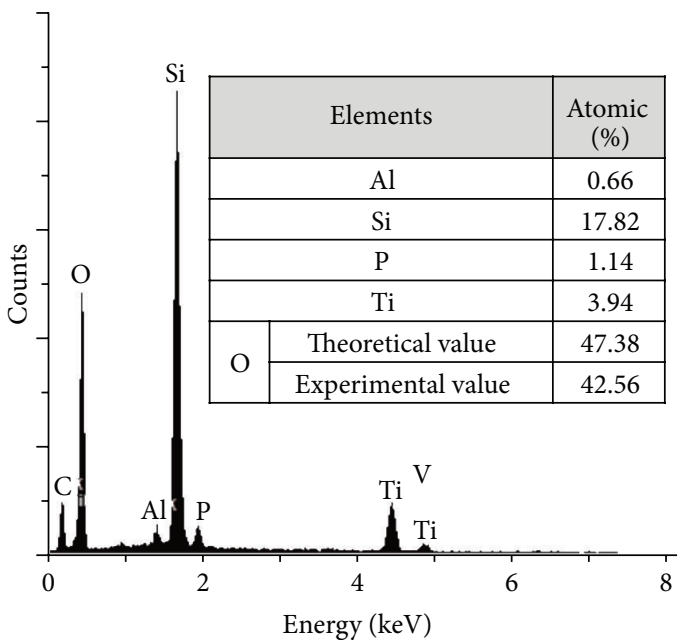

FIGURE 4: EDX spectrum and the coating composition for S1 $30 \mu \mathrm{m}$.

the treatment would result in a more uniform coating surface. Furthermore, powerful arcs causing coating damage can also be found from time to time during the PEO treatment [19]. Consequently, longer treatment times would result in more localized coating damage during the PEO process. This effect could also contribute to the larger pores found on S1.

It should be reemphasized that the PEO process is a conversion treatment which transforms the titanium alloy surface into $\mathrm{TiO}_{2}$. The electrolytes can modify the coating composition during the PEO process. As an example, the EDX spectrum and the coating composition for S1 $30 \mu \mathrm{m}$ are shown in Figure 4. The coating composition calculations based on EDX spectra for the four coating surfaces are given in Table 4. From Table 4, instead of $\mathrm{TiO}_{2}$, the substoichiometric oxide, which can be expressed as $\operatorname{Ti}_{n} \mathrm{O}_{2 n-1}$, is the coating structure. Gardos suggests that suboxides, also known as Magneli phases, could create a lubricating effect during sliding wear by decreasing the C.O.F. [20, 21].

3.2. POD Observations and Results. Optical micrographs of the POD wear tracks are shown in Figure 5. The coefficient of friction (C.O.F.) versus sliding distance $(m)$ is shown in Figure 6. S1 $20 \mu \mathrm{m}$ and S2 $20 \mu \mathrm{m}$ are performed in a very similar fashion under the POD testing. While the S2 $20 \mu \mathrm{m}$ coating remained at a lower C.O.F. (C.O.F. $\approx 0.2)$ for a greater distance than the $S 120 \mu \mathrm{m}$, both C.O.F. curves eventually overlapped (C.O.F. $\approx 0.65)$. According to research done in [16], abrasive wear dominated wear behaviour when C.O.F. $\approx 0.65$. In other words, the material transfer from the steel ball caused the sliding couple to change from steel versus Ti-based oxide coating to steel versus oxidised steel debris. On the other hand, S1 $30 \mu \mathrm{m}$ and S2 $30 \mu \mathrm{m}$ coatings showed siginificantly better results under POD testing. In both cases, the C.O.F. value remained around 0.13 for the entire duration of the testing. Furthermore, the wear tracks of the $30 \mu \mathrm{m}$ POD tests are siginificantly thinner and less noticable than the wear tracks of the $20 \mu \mathrm{m}$ POD tests.

One possible reason to explain this phenomenon is the presence of lubricious oxides. While the PEO coating process does not change, the PEO coating is not uniform. Rather, the $\mathrm{PEO}$ coating has a dense inner layer and a porous outer layer. As a result, it is likely that the chemical composition varies in ratio at different thicknesses of the PEO coating. As such, an abundance of lubricating oxides in one layer may account for the superior performance of the $30 \mu \mathrm{m}$ coatings over the $20 \mu \mathrm{m}$ coatings in the POD tests. In order to prove this theory, it is necessary to analyze the stoichometric ratios of the coating surfaces The stoichiomic analysis of the coatings surface calculated from the EDX analysis is shown in Table 4. The concentration of $\mathrm{Si}$ for $30 \mu \mathrm{m}$ coatings was much higher than that of the $20 \mu \mathrm{m}$ coatings. Consequently, doped $\mathrm{Si}$ is believed to make the most contribution to occupying oxygen from $\mathrm{Ti}$ and in creating lubricating oxides [16] based on EDX analysis and the comparison of the results obtained by POD tribotests [21].

The study on lubricating oxides is still relatively new and complicated. As a result, further research using instruments such as XPS (X-ray photoelectron spectroscopy), XAS (X-ray absorption spectroscopy), and TEM (transmission electron microscopy) will be needed to confirm this theory.

3.3. Inclined Sliding Test Observations and Results. Under normal circumstances, the inclined sliding test will result in two forms of damage to the coating. The first type of damage is peeling, which results in the complete removal of the coating and the exposure of the substrate material. The second type of damage is chipping, which results in the removal of the upper layer of the coating. However, chipping damage will still leave the lower dense layer adherent to the substrate $[16,22]$. A diagram of the coating failure behavior of the inclined impact sliding test is shown in Figure 7.

The OM images of the sliding tracks on S1 and S2 under $300 \mathrm{~N}$ of pressing load and 50 cycles are shown in Figure 8 where the typical areas of wear were also marked. The EDX analysis of these areas is shown in Figure 9. The estimated maximum lengths and widths of the peeled area are shown in Table 5.

After careful analysis of the samples, it can be seen that the S1 sample shows complete peeling in the sliding tracks. 


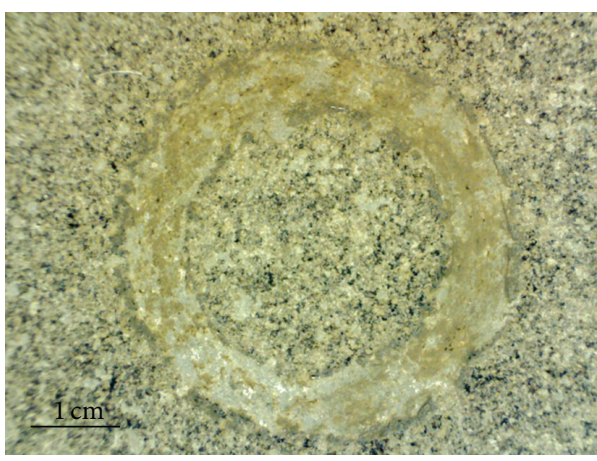

(a)

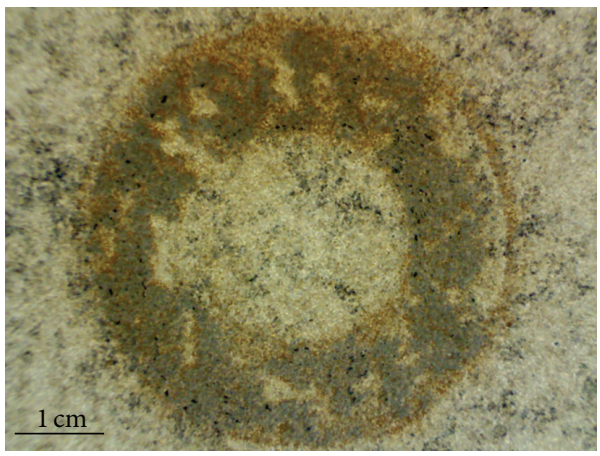

(c)

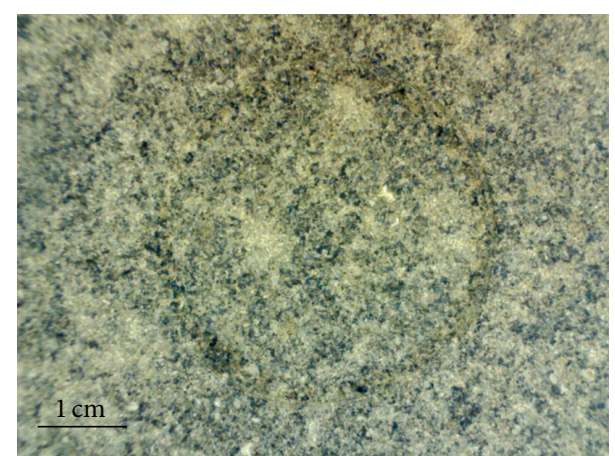

(b)

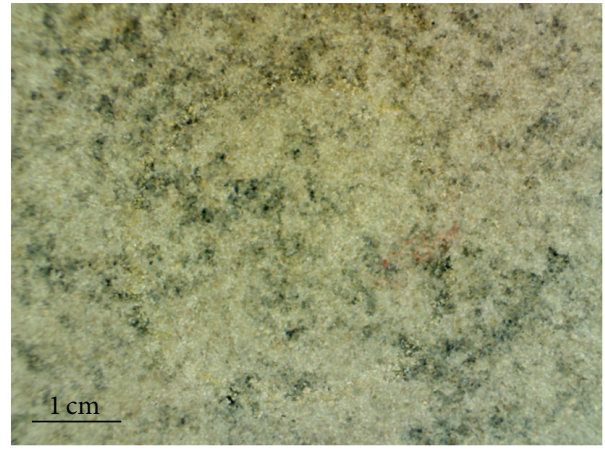

(d)

Figure 5: Optical micrographs of the four coating surfaces (a) S1 at $20 \mu \mathrm{m}$ thickness, (b) S1 at $30 \mu \mathrm{m}$ thickness, (c) S2 at $20 \mu \mathrm{m}$ thickness, and (d) S2 at $30 \mu \mathrm{m}$ thickness.

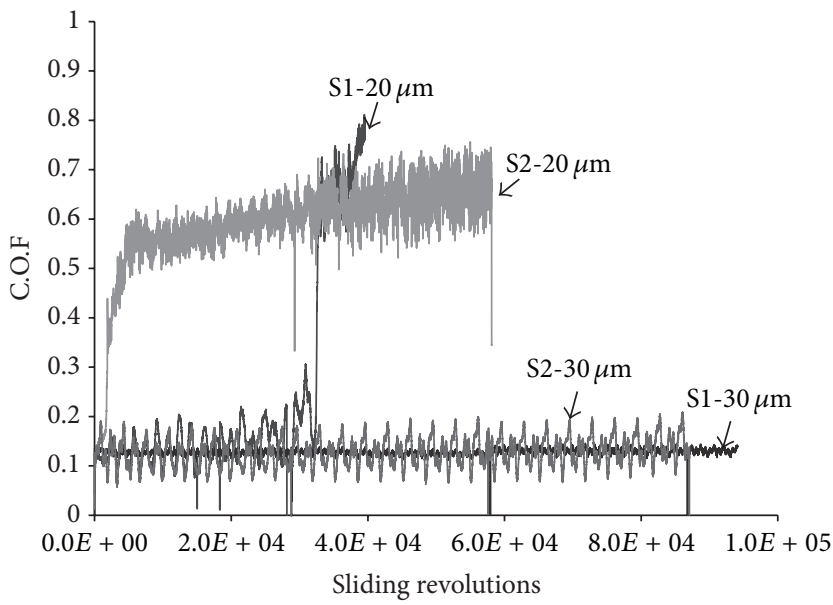

(a)

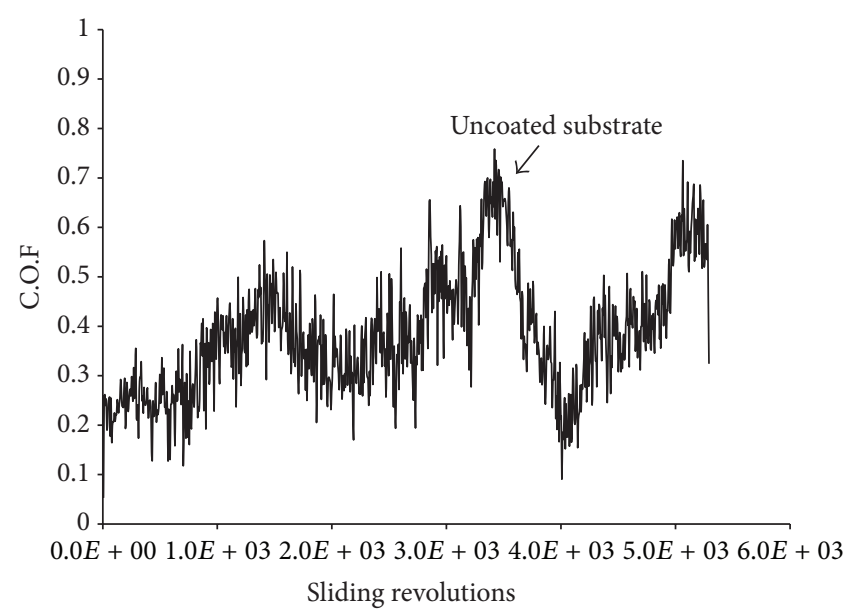

(b)

FIGURE 6: Coefficient of friction (C.O.F.) versus sliding distance $(m)$ on (a) both sides of $S 1$ and $S 2$ and (b) the uncoated substrate.

While the $20 \mu \mathrm{m}$ surface did prove to be more resistant to chipping damage than the $30 \mu \mathrm{m}$ surface, both coatings still fail to prevent substrate exposure. On the other hand, the S2 sample proved to have slightly better results compared to the S1 sample. Although both sliding tracks on the S2 also show substrate exposure, the estimated widths of the peeled area in S2 sliding tracks are slightly lower than those of the S1 sliding tracks. As a result, the exposed substrate areas on the S2 samples are smaller than those on the S1. Furthermore, much of the exposed areas on the S2 sliding tracks seem to have a high concentration of $\mathrm{Si}$ as shown in the diagram $\mathrm{C}$ of Figure 9. As such, some of the damage caused by peeling 


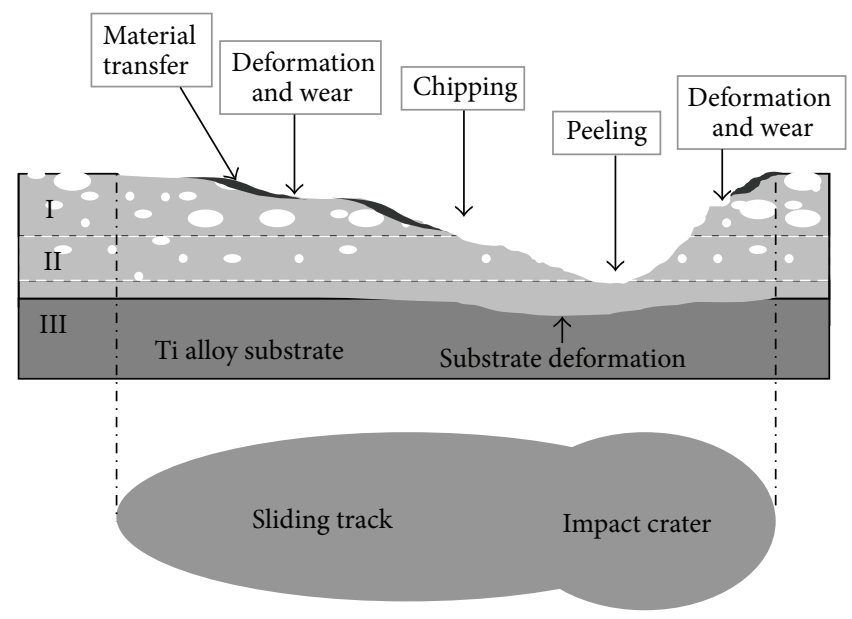

FIGURE 7: A diagram of the coating failure behavior of the inclined impact sliding test [16].

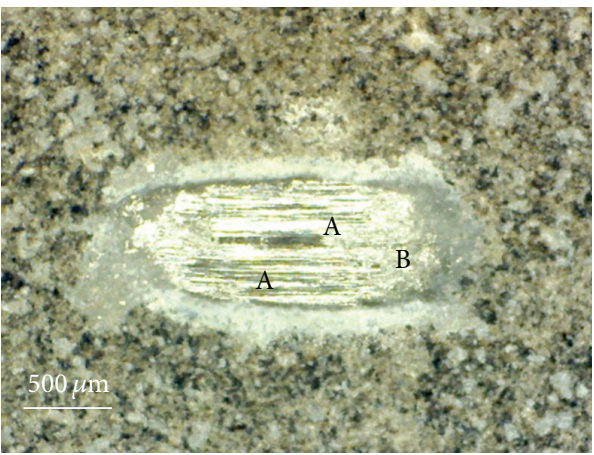

(a)

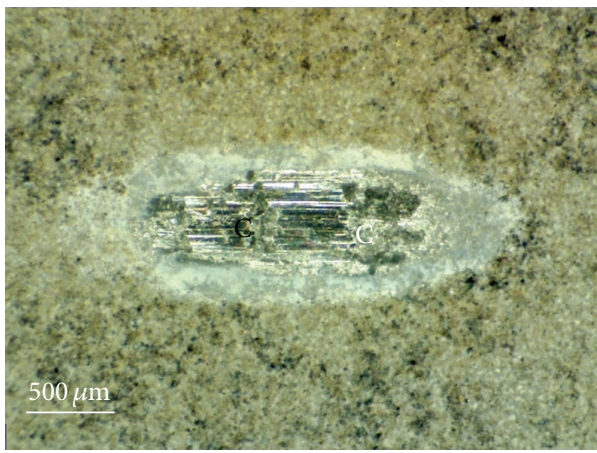

(c)

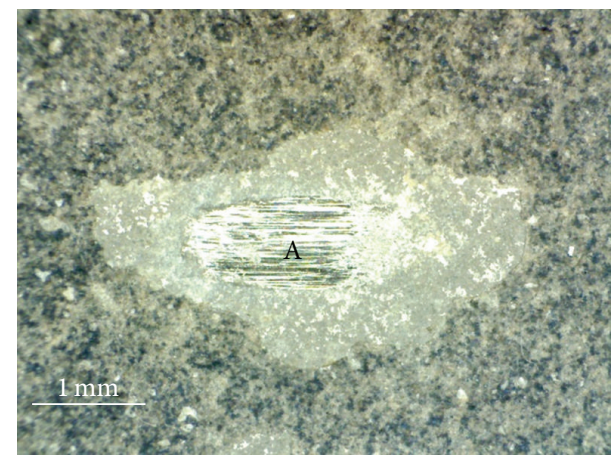

(b)

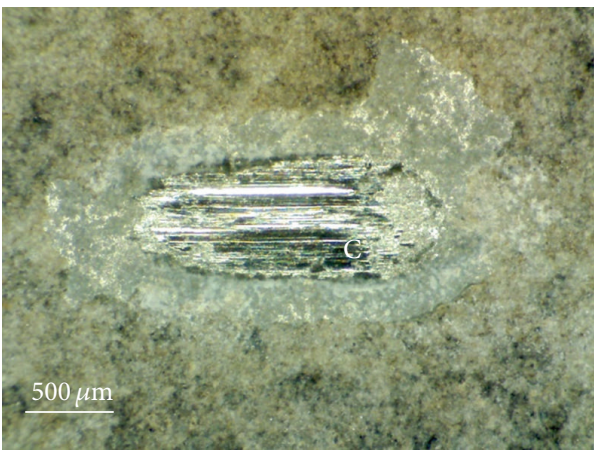

(d)

Figure 8: OM images of the four sliding tracks (a) S1 at $20 \mu \mathrm{m}$ thickness, (b) S1 at $30 \mu \mathrm{m}$ thickness, (c) S2 at $20 \mu \mathrm{m}$ thickness, and (d) S2 at $30 \mu \mathrm{m}$ thickness under $300 \mathrm{~N}$ of pressing load and 50 cycles with marked typical wear failure areas.

resulted only in partial exposure of the substrate due to the high presence of $\mathrm{Si}$, indicating that the inner layer of the coating still existed.

One possible explanation for the superior results of the S2 sample is the difference between the surface morphology of the two samples. As mentioned earlier, the pores on S2 are much smaller than the pores on S1. Consequently, the smaller pores may have allowed the coating to have a higher cohesion. It seems that the coating cohesion strength influenced by the pore size and distribution had played a critical role. As a result, the performance of the coatings during the inclined sliding under very high load condition could be ranked in a descending order of S2-A, S2-B, S1-A, and S1-B. The dimensions of damaged areas of the coatings are shown in Table 5. Such results were believed to be caused by the inclined sliding test method which introduced additional shear stresses into the coating beyond the pure sliding friction effect as observed in the previous POD test section.

The inclined sliding test is still a relatively new method of experimentation. As a result, further tests measuring the 


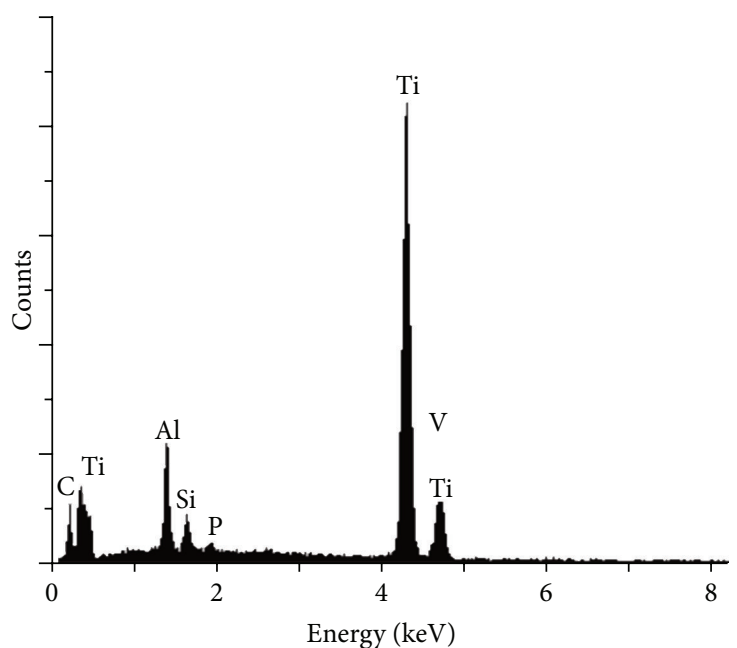

(a)

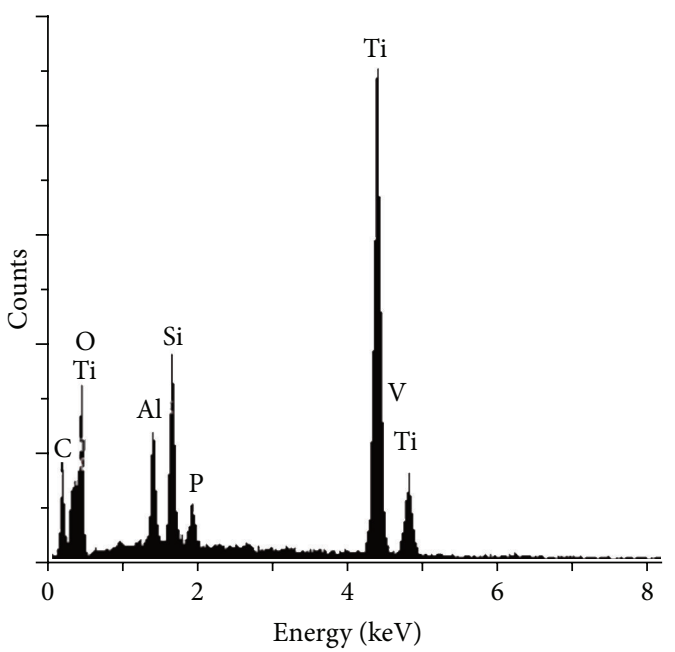

(b)

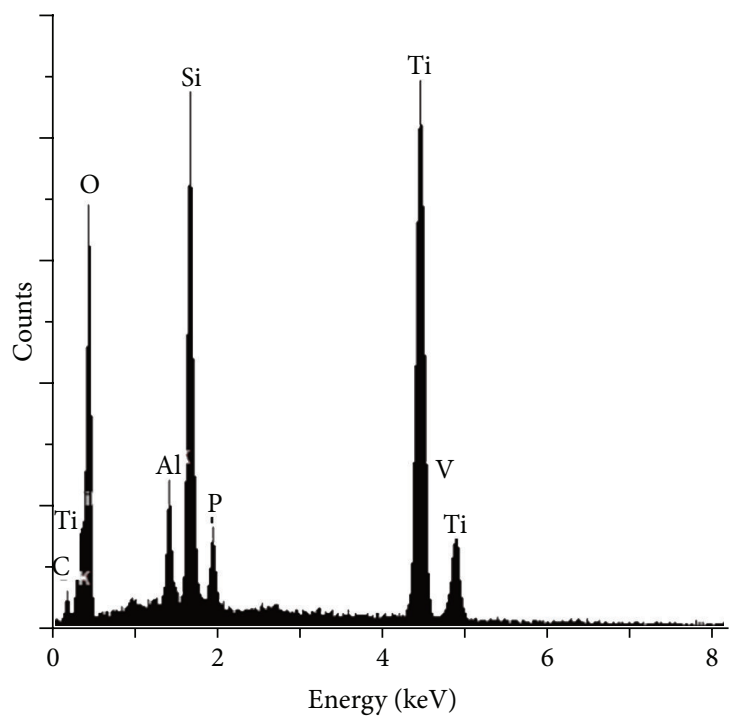

(c)

FIGURE 9: EDX analysis of typical areas shown in Figure 8.

TABLE 5: Estimated maximum width and maximum length of the area caused by peeling damage in samples S1 and S2.

\begin{tabular}{lcc}
\hline Sample & Maximum width $(\mathrm{mm})$ & Maximum length $(\mathrm{mm})$ \\
\hline S1 $20 \mu \mathrm{m}$ & 0.83 & 1.7 \\
S1 $30 \mu \mathrm{m}$ & 0.81 & 1.9 \\
S2 $20 \mu \mathrm{m}$ & 0.58 & 1.7 \\
S2 $30 \mu \mathrm{m}$ & 0.67 & 1.7 \\
\hline
\end{tabular}

amount of coating loss, material transfer from the steel ball, wear of the steel ball, and depth of the wear track will still be needed to fully understand the performance of PEO coatings under the inclined sliding test. Furthermore, coating roughness, which was not taken into account in this experiment, could also influence the results of the sliding tracks on the two samples.

\section{Conclusions}

By using a bipolar power supply mode during deposition process, 4 PEO coatings were made and then polished to a thickness of either $20 \mu \mathrm{m}$ or $30 \mu \mathrm{m}$. Afterwards the PEO coatings underwent POD testing and inclined sliding testing to study coating failure behaviour under prolonged wear circumstances and high stress conditions. The POD test demonstrated that the manipulation of stoichiometric composition of the PEO coating had a great effect on the performance of the coating under prolonged wear circumstances. In the $30 \mu \mathrm{m}$ coatings, higher Si concentration compared to that of the $20 \mu \mathrm{m}$ coatings revealed that doped Si makes the most contribution to occupying oxygen from $\mathrm{Ti}$ and in creating lubricating oxides. As a result, these lubricating oxides allowed the C.O.F. of the $30 \mu \mathrm{m}$ coatings to remain low and the wear track to stay small and unnoticable for the extended 
POD testing. On the other hand, the lower concentration of $\mathrm{Si}$ in the $20 \mu \mathrm{m}$ coatings caused the C.O.F. to increase drastically and the wear track to become much wider after a certain period of testing. As a result, the presence of $\mathrm{Si}$ in the PEO coating of Ti-6Al-4V contributes to the wear resistence of the coating.

In the inclined sliding tests, the smaller pores found in the PEO coatings from S2 were believed to be the reason why the S2 PEO coatings outperformed the S1 PEO coatings. As a result, much of the substrate was only partially exposed on the S2 coatings rather than completely exposed as on the S1 coatings after the tests. The difference in the test results was likely due to the inclined sliding test method which introduced additional high shear stresses in the coating. The coating cohesion strength would be a decisive factor to the coating performance. The less porous the coating, the higher the cohesion strength. Thus, S2 outperformed S1.

On the one hand, the inclined sliding test was conducted at a stress condition much higher than that of normal operation, which caused an accelerated coating failure. On the other hand, the PEO coating on Ti-6Al-4V does have limitations in withstanding extremely high contact sliding loads. As a result, more research needs to be done on PEO coating before it should be used practically in sustaining great wear forces such as those found in aerospace applications. However, the results of this study demonstrated that while the PEO coating may not perform well under intense wear, it did show minimum wear failure behaviour in the POD tests. As a result, the $\mathrm{PEO}$ coating on $\mathrm{Ti}-6 \mathrm{Al}-4 \mathrm{~V}$ has great potential for aerospace components such as fastners and disks that sustain low but prolonged wear.

\section{Conflict of Interests}

The authors declare that there is no conflict of interests regarding the publication of this paper.

\section{Acknowledgment}

The research was supported by Natural Sciences and Engineering Research Council of Canada.

\section{References}

[1] A. L. Yerokhin, X. Nie, A. Leyland, and A. Matthews, "Characterisation of oxide films produced by plasma electrolytic oxidation of a Ti-6Al-4V alloy," Surface and Coatings Technology, vol. 130, no. 2-3, pp. 195-206, 2000.

[2] J.-G. Kim, K.-R. Lee, and S.-J. Yang, "Wear-corrosion performance of Si-DLC coatings on Ti-6Al-4V substrate," Journal of Biomedical Materials Research A, vol. 86, no. 1, pp. 41-47, 2008.

[3] H. C. Man, M. Bai, and F. T. Cheng, "Laser diffusion nitriding of Ti-6Al-4V for improving hardness and wear resistance," Applied Surface Science, vol. 258, no. 1, pp. 436-441, 2011.

[4] T. Cheng, Y. Chen, and X. Nie, "Surface morphology manipulation and wear property of bioceramic oxide coatings on titanium alloy," Surface and Coatings Technology, vol. 215, pp. 253-259, 2013.
[5] A. L. Yerokhin, X. Nie, A. Leyland, A. Matthews, and S. J. Dowey, "Plasma electrolysis for surface engineering," Surface and Coatings Technology, vol. 122, no. 2-3, pp. 73-93, 1999.

[6] C. Martini, L. Ceschini, F. Tarterini, J. M. Paillard, and J. A. Curran, "PEO layers obtained from mixed aluminate-phosphate baths on Ti-6Al-4V: dry sliding behaviour and influence of a PTFE topcoat," Wear, vol. 269, no. 11-12, pp. 747-756, 2010.

[7] X. Nie, A. Leyland, and A. Matthews, "Low temperature deposition of $\mathrm{Cr}(\mathrm{N}) / \mathrm{TiO}_{2}$ coatings using a duplex process of unbalanced magnetron sputtering and micro-arc oxidation," Surface and Coatings Technology, vol. 133-134, pp. 331-337, 2000.

[8] J. M. Wheeler, C. A. Collier, J. M. Paillard, and J. A. Curran, "Evaluation of micromechanical behaviour of plasma electrolytic oxidation (PEO) coatings on Ti-6Al-4V," Surface and Coatings Technology, vol. 204, no. 21-22, pp. 3399-3409, 2010.

[9] F. C. Walsh, C. T. J. Low, R. J. K. Wood et al., "Plasma electrolytic oxidation (PEO) for production of anodised coatings on lightweight metal (Al, mg, Ti) alloys," Transactions of the Institute of Metal Finishing, vol. 87, no. 3, pp. 122-135, 2009.

[10] R. O. Hussein, X. Nie, and D. O. Northwood, "A spectroscopic and microstructural study of oxide coatings produced on a Ti-6Al-4V alloy by plasma electrolytic oxidation," Materials Chemistry and Physics, vol. 134, no. 1, pp. 484-492, 2012.

[11] T. Cheng, Y. Chen, and X. Nie, "Insertion torques influenced by bone density and surface roughness of $\mathrm{HA}-\mathrm{TiO}_{2}$ coatings," Thin Solid Films, vol. 549, pp. 123-130, 2013.

[12] A. Alabbasi, M. Kannan, R. Walter, M. Störmer, and C. Blawert, "Performance of pulsed constant current silicate-based PEO coating on pure magnesium in simulated body fluid," Materials Letters, vol. 106, pp. 18-21, 2013.

[13] Z. Peng, Plasma electrolytic oxidation (PEO) coatings on an A356 alloy for improved corrosion and wear resistance [Ph.D. thesis], 2013, Paper 4764.

[14] Y. Chen and X. Nie, "Study on fatigue and wear behaviors of a TiN coating using an inclined impact-sliding test," Surface and Coatings Technology, vol. 206, no. 7, pp. 1977-1982, 2011.

[15] J. F. Su, D. Yu, X. Nie, and H. Hu, "Inclined impact-sliding wear tests of $\mathrm{TiN} / \mathrm{Al}_{2} \mathrm{O}_{3} / \mathrm{TiCN}$ coatings on cemented carbide substrates," Surface and Coatings Technology, vol. 206, no. 7, pp. 1998-2004, 2011.

[16] Y. Chen, T. Cheng, and X. Nie, "Wear failure behaviour of titanium-based oxide coatings on a titanium alloy under impact and sliding forces," Journal of Alloys and Compounds, vol. 578, pp. 336-344, 2013.

[17] Federal Aviation Administration (FAA), "Chapter 13: aircraft landing gear systems," in Aviation Maintenance Technician Handbook-Airframe, vol. 2 of FAA Handbooks Series, pp. 131-13-3, 2012.

[18] http://www.amesweb.info/HertzianContact/HertzianContact .aspx.

[19] A. L. Yerokhin, X. Nie, A. Leyland, A. Matthews, and S. J. Dowey, "Plasma electrolysis for surface engineering," Surface and Coatings Technology, vol. 122, no. 2-3, pp. 73-93, 1999.

[20] M. N. Gardos, "Magnéli phases of anion-deficient rutile as lubricious oxides. Part I. Tribological behavior of single-crystal and polycrystalline rutile $\left(\mathrm{Ti}_{n} \mathrm{O}_{2 n-1}\right)$," Tribology Letters, vol. 8, no. 2-3, pp. 65-78, 2000.

[21] M. N. Gardos, "Magnéli phases of anion-deficient rutile as lubricious oxides. Part II. Tribological behavior of $\mathrm{Cu}$-doped polycrystalline rutile $\left(\mathrm{Ti}_{n} \mathrm{O}_{2 n-1}\right)$," Tribology Letters, vol. 8, no. 2-3, pp. 79-96, 2000. 
[22] Y. Chen and X. Nie, "Study of the fatigue wear behaviors of a tungsten carbide diamond-like carbon coating on 316L stainless steel," Journal of Vacuum Science \& Technology A, vol. 30, Article ID 051506, 2012. 

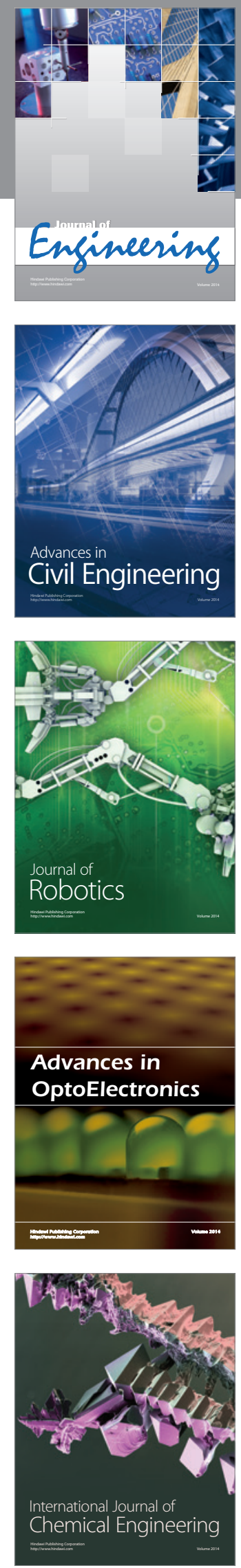

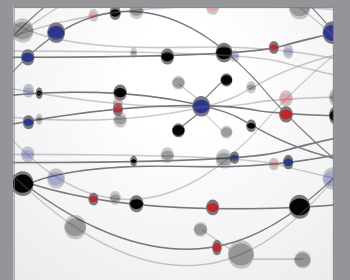

The Scientific World Journal
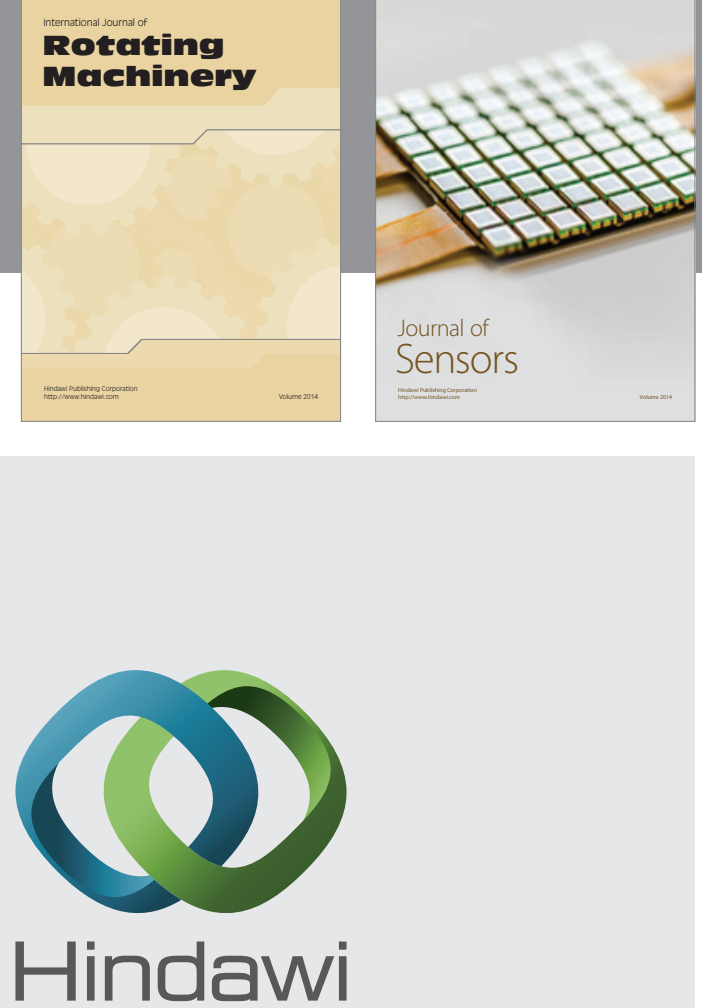

Submit your manuscripts at http://www.hindawi.com
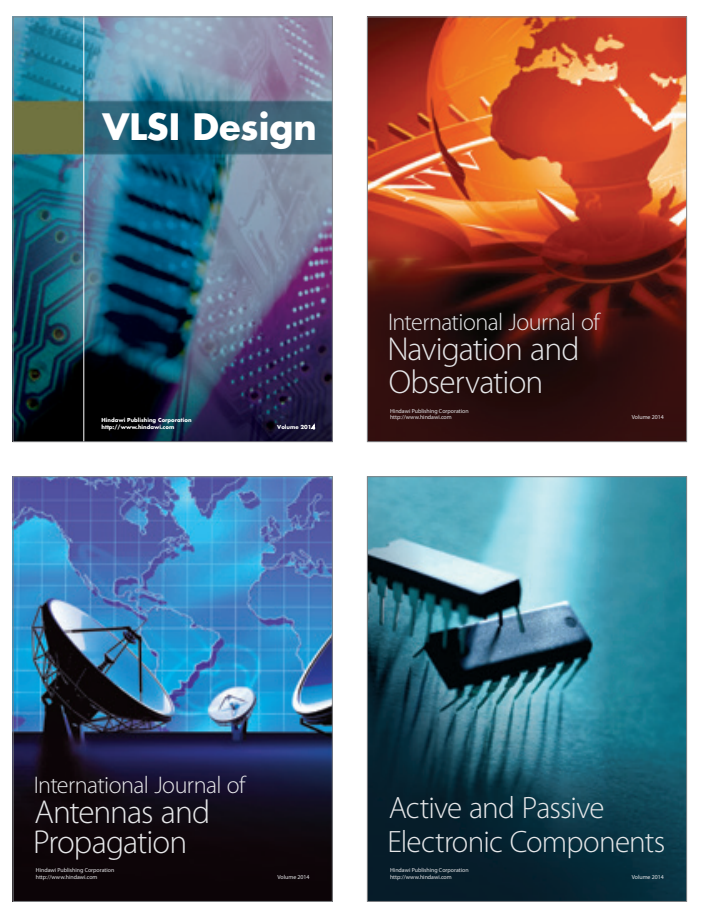
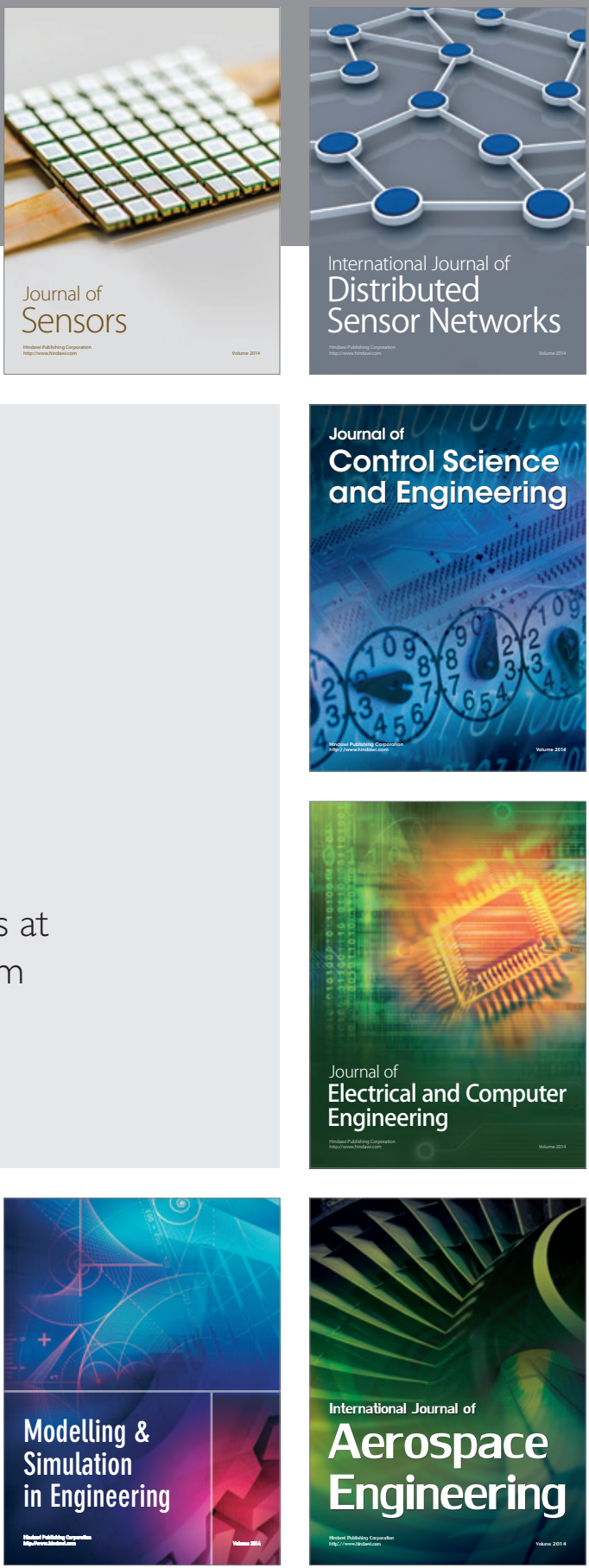

Journal of

Control Science

and Engineering
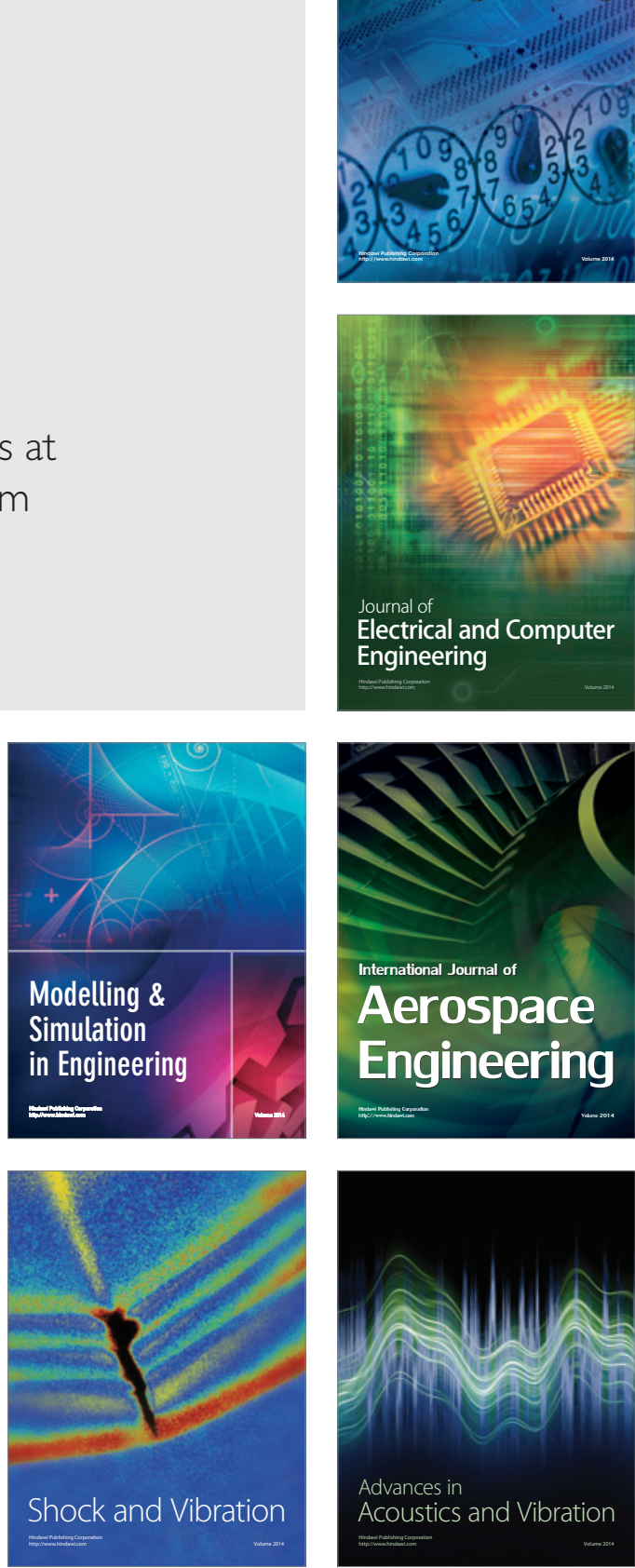